\title{
SOME SIMPLE TECHNIQUES FOR COATING HEAT-SENSITIVE SEM SPECIMENS
}

\author{
L. F. Allard and W. C. Bigelow \\ Department of Materials Engineering, The University of Michigan, Ann Arbor, MI 48109, U.S.A.
}

Delicate biological SEM specimens have been shown to suffer surface damage during coating by DC diode sputtering (Ingram et al., 1976; Holland, 1976). This process causes a rise in temperature of thermally insulating samples, which can create damage effects that range from small holes in membranes to complete sample melting (Ingram et al., 1976; Holland, 1976; DeNee and Walker, 1975; Panayi et al., 1977). Various measurements (Echlin, 1975; Allard et al., 1977) of the temperature rise indicate increases of $60^{\circ} \mathrm{C}$ to $110^{\circ} \mathrm{C}$ during the first minute of the coating cycle. This temperature increase is due to $I^{2} R$ heating by the conduction through the sample of electrons released during the sputtering process. To minimize this effect, Ingram et al. (1976) in 1976 introduced the triode sputterer, which conducts electrons to ground through an electrode charged positively with respect to the sample. Temperature increases were greatly reduced during triode sputtering, but were still high enough to cause melting of organic crystals at $53^{\circ} \mathrm{C}$.

Recently, Panayi et al. (1977) have described the planar magnetron "cool" sputtering system, which uses a magnetic field to remove electrons from the glow discharge region surrounding the sample. Thin wire thermocouples suspended in the plasma at the position of the sample surface never indicated a temperature above $40^{\circ} \mathrm{C}$ with this technique. Extremely delicate styrofoam which melts within the first three seconds of conventional DC diode sputtering was coated with no apparent degradation of the cell structure. However, planar magnetron systems are expensive to buy or construct, whereas most SEM labs are presently equipped with DC diode sputtering systems. We have devised an inexpensive modification to the DC diode sputter coater, and coating techniques which give results comparable to planar magnetron sputtering.

With our technique, a motor-cam-microswitch arrangement on the primary side of the high voltage power supply turns the voltage on and off, "pulsing" the glow discharge so it is $\mathrm{ON}$ one second in every three. At this rate, heat buildup during the $\mathrm{ON}$ cycle dissipates during the OFF cycle. A thin wire thermocouple suspended within the plasma at the usual sample position indicated a reduction in temperature from $120^{\circ} \mathrm{C}$ to $40^{\circ} \mathrm{C}$ with this technique. A similar temperature reduction is indicated for samples placed on their side at the edge of the coating chamber, so the sample is extended to the glow discharge but facing the center of the chamber. Since the samples are outside the plasma, few electrons are conducted through them, and the temperature increase is slight. Coupling these two techniques, samples can be coated at the side of the chamber, while the glow discharge is pulsed as before. No significant temperature increase above room temperature can be measured with this technique. Styrofoam fracture surfaces coated with these techniques show little or no surface damage, indicating these processes are similar in effectiveness to the planar magnetron sputtering process, and much less expensive.

\section{REFERENCES}

Allard, L. F., Thomas, P. D., Bigelow, W. C. and Kirchoff, B., 1977. Proc. EMSA, 70.

DeNee, P. B. and Walker, E. R., 1975. IITRI/SEM, 225. Echlin, P., 1975. IITRI/SEM, 218.

Holland, V. F., 1976. IITRI/SEM, 72.

Ingram, P., Morosoff, N., Pope, L., Allen, F. and Tisher, C., 1976. IITRI/SEM, 76.

Panayi, P. N., Cheshire, D. C. and Echlin, P., 1977. IITRI/SEM, 463. 